\title{
ASSESSMENT OF MEDICATION ADHERENCE AMONG ELDERLY PATIENTS IN MYSURU CITY
}

\author{
JAIDEV KUMAR ${ }^{1}$, MAHENDRAPPA ${ }^{2}$, PRAMOD KUMAR ${ }^{3}$ \\ Department of Paediatric, JSS Medical College and Hospital, S. S. Nagar, Mysore 570015 \\ Email: kbmahenappa@jssuni.edu.in
}

Received: 12 May 2019, Revised and Accepted: 15 Jul 2019

\begin{abstract}
Objective: To assess medication adherence among patients with chronic diseases.

Methods: This was a prospective observational study carried out over period of one year in mysuru city. The subjects who meet study criteria were enrolled in this research study. The enrolled subjects were administered with simplified medication adherence questionnaire. The criteria to establish adherent and non-adherent were calculated as per simplified medication adherence questionnaire directions.

Results: The gender distribution of this research study was reflected with male accountable for $45.63 \%$ followed by female $54.36 \%$. Asper simplified medication adherence questionnaire $88 \%$ were adherent and remaining $12 \%$ were non-adherent in this research study.

Conclusion: Patients with good adherence in this research study showed that they have good literacy status as well as better awareness about the existing medical condition and more consciousness may be there among these patients, what will be going to happen if their medical condition is left untreated.46.29\% males and $59.58 \%$ females were adherent in this research study followed by $59.24 \%$ were adherent in the age range of 60 $70 \mathrm{y}$ as they were more conscious and less forgetfulness about medications as per the directions given by patient consultant which was oral feedback taken by research investigators during medication review in subjects home.
\end{abstract}

Keywords: Elderly, Medication, Adherence, Chronic Diseases

(C) 2019 The Authors. Published by Innovare Academic Sciences Pvt Ltd. This is an open access article under the CC BY license (http://creativecommons.org/licenses/by/4.0/] DOI: http://dx.doi.org/10.22159/ijcpr.2019v11i5.35701

\section{INTRODUCTION}

Medication adherence is defined as patient needs to follow directions as per instructions given by patient consultant with respect to medications [1]. Chronic disorders like Asthma, Hypertension, and Diabetes Mellitus etc are incurable medical conditions, where patient has to take medications throught their life as per the directions given by patient consultant without fail [2]. More importantly patient has to be made awareness about the causes and risk factors of existing medical problem as well as consequences that can result if medications are not taken at right time [3]. Hypertension and Diabetes Mellitus are common risk factors for most of cardiovascular medical conditions such as Coronary Artery Disease, Congestive Heart Failure, Myocardial Infarction and Chronic Kidney Disease, where vital parameters such as blood pressure, blood sugar, and forced expiratory volume has to be well controlled by receiving medications as per the patient consultant. In other words medication adherence is defined as whether patient behaviour is able to meet the requirements of prescriber in terms of prescribed regimen as well as nonpharmacological measures that needs to be followed in that specific medical conditions [4]. There was one overseas research study carried out with respect to adherence of antihypertensive medications that had reflected poor health outcomes of patients when they did not follow the directions of patient consultant [5]. Patient's failure to receive medications as per the directions of prescriber can always result into further progression of disease and can ultimately result into complications of respective medical condition [6]. There are certain patients who have not realised that medications should be taken throught their life for chronic medical conditions such as hypertension, diabetes mellitus, hyperlipidaemia accompanied by monitoring certain vital parameters such as blood pressure, blood sugar levels etc which could be the ultimate reason for medication non-adherence [7]. The overseas research study showed that uncontrolled blood pressure due to medication nonadherence can result 7.6 million premature mortality followed by 92 million disability adjusted life years resulted due to high blood pressure [8]. According to this research study 2095 research articles that were reviewed showed that medication non-adherence occurred when an individual deviates from the direction of prescriberv [9]. The medication adherence defined as per this research study was patient needs to follow the directions of medication administration followed by food diet and life style habits as per the directions given by prescriber. Survey conducted in 20032004 showed that $37 \%$ of hypertensive were having controlled blood pressure, while rest of the hypertensives were having uncontrolled blood pressure due to poor medication adherence [10]. According to WHO uncontrolled blood pressure is always associated with poor medication adherence and only 20 to $80 \%$ of patients will always have well controlled blood pressure as they follow the directions of concerned prescriber. Different research studies have reflected that common causes of medication non-adherence can be attributed to complexity of pharmacological treatment followed by side effects of medications, communication gap between patient and doctor, patient unwillingness to follow the health care system, economically poor patient may not afford to purchase medications, socioeconomic factors, sociodemographic factors, medical expenditure and lack of health care insurance [11]. This research study was designed with intention of evaluating antihypertensive medications adherence at Nedjo General Hospital and the reasons to find out different reasons for medications non-adherence were explored [12].

One of the research work carried out in overseas on medication adherence reflected that failure of therapy was due to medication nonadherence [13]. The countries which have taken proper steps to improve medication adherence had shown good health status among individuals of respective medical conditions. The medication adherence attaining to higher levels can be influenced by following factors such as intake of the appropriate medicine, followed by receiving correct medicine at right time at the right dosage for the recommended duration without taking any over the counter medication until and unless it is directed by patient consultant. According to this research study medication adherence persisted for long period of time can always influence better clinical outcomes of patients. According to the WHO patient determinants are influenced by five factors, among that only one factor was associated with patient element [14]. Those factors are social and economic-related factors eg poor socioeconomic status, low level of literacy; healthcare system/healthcare team-related factors eg poor medication distribution 
systems and overworked healthcare providers; therapy related factors were associated with duration of medicine treatment, past medication treatment failures and any medication treatment beneficial effects; medical condition-related factors such as severity of symptoms, level of disability and availability of effective treatments and finally patient related factors are associated with not trusting diagnosis done by patient consultant, forgetting to take medicines at right time due to busy working schedule and there is no encouragement to take medicines as per doctor directions. Whenever there is medication adherence issues are there, interventions should be done in according to the underlying cause of medication adherence [7].

There are older research studies were carried out with regarding to medication adherence by applying different types of adherence tools which goes on changing from time to time. Research investigators have designed this research study to know proper assessment behind medication non-adherence by finding different reasons and how medication adherence problems can be overcome by adopting good strategies in future.

\section{Objective of the study}

To assess medication adherence among study participants with chronic diseases.

\section{MATERIALS AND METHODS}

\section{Methodology}

This was a prospective observational study carried out over a period of one year in mysuru city. The study participants who meet study criteria were enrolled in these research study. The study criteria that was incorporated in this research study were age equivalent 60 $\mathrm{y}$ and more than this of all gender followed by any study participant diagnosed with chronic medical conditions and any study participant diagnosed with cancer and not willing to participate in this research study were excluded. The demographic details such as age, gender, marital status, followed by social history, qualification status were documented in suitably designed data collection form. The enrolled subjects were administered with simplified medication adherence questionnaire. The response obtained by enrolled subjects for simplified medication adherence questionnaire were recorded in goggle excel data base. The criteria to establish adherent and non-adherent were calculated as per Simplified Medication Adherence Questionnaire. Research investigators had administered this Simplified Medication Adherence Questionnaire to enrolled subjects when medicine review was done in patient home. English questionnaire was translated into Kannada and administered depending upon the necessity enrolled subjects. A positive response to any of the qualitative questions, more than two doses missed over the past week, or over two days of total non-medication during the past three months were considered as non-adherent.

\section{RESULTS AND DISCUSSION}

Simplified Medication Adherence Questionnaire were administered to the enrolled subjects who met study criteria in Mysore city for the last one year. When research investigator was administering questionnaire to the subjects, some subjects did not show any interest for answering the questions without any valid reasons, those subjects were not taken into consideration for this research study. The questionnaire administered to the subjects was translated into Kannada language. Among 455 enrolled subjects 100 subjects did not complete the questionnaire where these subjects were excluded from this research study. Research investigators had faced tough time to convince some subjects for getting reply for questions reflected in simplified medication adherence questionnaire. Some subjects had given answers by WhatsApp after two or three days of questionnaire administered. Subjects who were busy to give answer for questionnaire was given time to get back to research investigators for replying answer as early as possible. Travelling from one patient destination to another patient destination was time consuming for research investigators. Even though research investigators had shown lot of patience to sustain the momentum of this research study.

Research investigators initially had bitter experience as some of the patients did not permit to enter respective patient home, thinking that research investigators were strangers, even though research investigators came in good appearance with college identity and apron wearing. Subjects who did not adhere to medications were found to have following reasons such as forgetfulness, confusion, busy schedule of the day which makes difficult for the patient to follow the directions given by concerned consultant where similar findings was observed in Pirasath where hypertensive patients did not adhere to medications due to forgetfulness and interruptions of daily routine [1]. Subjectsnon-adherent in this research study gave reasons such as confusion, difficulty to remember the instructions as per doctor advice which was more accountable for subjects receiving more number of medications i. e more than six medications/day, some patients expressed that allopathic medicines did not yield results in according to their expectations which ultimately made them to ignore the medications and finally there were few subjects who have forgotten to take medicines as there were no health care takers, which ultimately frustrated them to adhere medications due to aging problems. Our research study findings were similar to that of Pirasath researchfindings [1].

Mohammed Gebre Dedefo1 research study reflected that medication adherence of hypertensives were assessed by Morsiky 8 item medication adherence questionnaire reflecting that any patients suffering from chronic medical condition can be screened for medication adherence with the help of this questionnaire [2]. The reason behind this may be questions framed in this questionnaire are easy to understand patients, so that they can give response immediately. Therefore our research study also hadsimilar opinion stating that questions framed in simplified medication adherence questionnaire were easy to understand, so that majority of participated subjects had given correct answer without any confusion and the subjects who had confusion regarding any questions in questionnaire were properly clarified with research investigators so that correct responses were given by participated subjects [2].

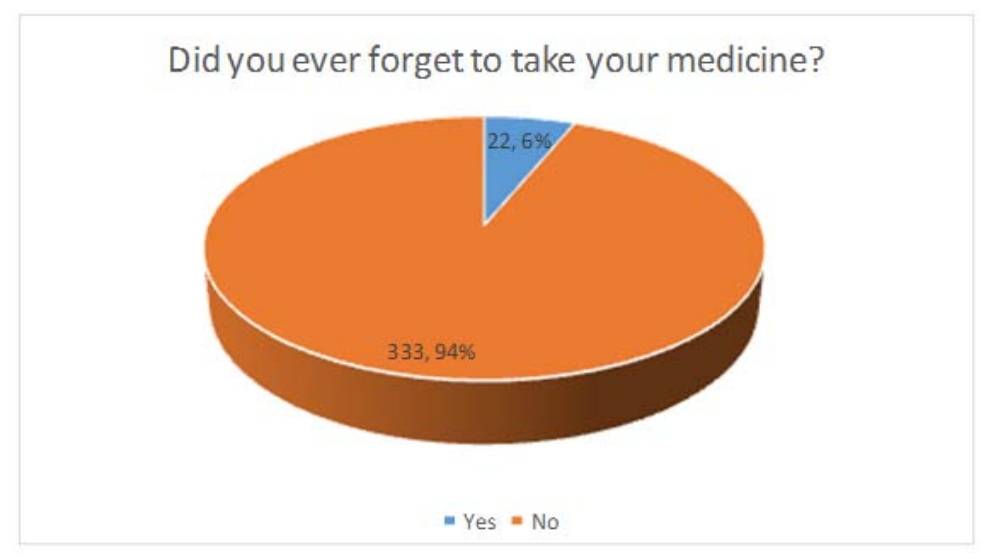

Fig. 1: Did you ever forget to take your medicine 
Table 1: Demographic details of the subject's total number of subject's enrolled was-355

\begin{tabular}{|c|c|c|c|}
\hline S. No. & Gender & Total number & Percentage \\
\hline 1 & Male & 162 & 45.63 \\
\hline 2 & Female & 193 & 54.36 \\
\hline \multicolumn{4}{|c|}{ Qualification status of enrolled subjects } \\
\hline 3 & Illiterate & 141 & 39.71 \\
\hline 4 & I Standard-V Standard & 45 & 12.67 \\
\hline 5 & VI Standard-X Standard & 41 & 11.54 \\
\hline 6 & SSLC & 56 & 15.77 \\
\hline 7 & II PUC & 36 & 10.14 \\
\hline 8 & Degree & 24 & 6.76 \\
\hline 9 & Post Graduate Degree & 08 & 2.25 \\
\hline 10 & PhD & 04 & 1.12 \\
\hline \multicolumn{4}{|c|}{ Age range of enrolled subjects } \\
\hline 11 & $60-70 \mathrm{Y}$ & 238 & 67.04 \\
\hline 12 & $71-80 \mathrm{Y}$ & 56 & 15.77 \\
\hline 13 & $81-90 \mathrm{Y}$ & 51 & 14.36 \\
\hline 14 & $91-100 \mathrm{Y}$ & 10 & 2.81 \\
\hline \multicolumn{4}{|c|}{ Marital status of enrolled subjects } \\
\hline 15 & Male with married & 352 & 99.15 \\
\hline 16 & Male without married & 03 & 0.84 \\
\hline 17 & Female with married & 351 & 98.87 \\
\hline \multirow{2}{*}{18} & Female without married & 01 & 0.28 \\
\hline & Widow & 03 & 0.84 \\
\hline \multicolumn{4}{|c|}{ Social history of enrolled subjects } \\
\hline 19 & Male Smoker & 107 & 30.14 \\
\hline 20 & Male without Smoker & 248 & 69.85 \\
\hline 21 & Female Smoker & Nil & 00 \\
\hline 22 & Female without Smoker & 355 & 100 \\
\hline 23 & Male with Alcoholism & 49 & 13.80 \\
\hline 24 & Male without Alcoholism & 306 & 86.19 \\
\hline 25 & Female with Alcoholism & 02 & 0.56 \\
\hline 26 & Female without Alcoholism & 353 & 99.43 \\
\hline
\end{tabular}

Table 2: Statistics of medication adherence in according to gender

\begin{tabular}{llll}
\hline S. No. & Gender & Adherent and percentage & Non-adherent and percentage \\
\hline 01 & Male & 75 and $46.29 \%$ & 87 and $53.70 \%$ \\
02 & Female & 115 and $59.58 \%$ & 78 and $40.41 \%$ \\
\hline
\end{tabular}

Table 3: Statistics of medication adherence in according to age range of subjects

\begin{tabular}{llll}
\hline S. No. & Age range & Adherent and percentage & Non-adherent and percentage \\
\hline 01 & $60-70 \mathrm{Y}$ & 141 and $59.24 \%$ & 97 and $40.75 \%$ \\
02 & $71-80 \mathrm{Y}$ & 24 and $42.85 \%$ & 32 and $57.14 \%$ \\
03 & $81-90 \mathrm{Y}$ & 28 and $54.90 \%$ & 23 and $45.09 \%$ \\
04 & $91-100 \mathrm{Y}$ & 04 and $40 \%$ & 06 and $60 \%$ \\
\hline
\end{tabular}

Table 4: Statistics of medication adherence in according to qualification status of subjects

\begin{tabular}{llll}
\hline S. No. & Qualification status & Adherent and percentage & Non-adherent and percentage \\
\hline 01 & Illiterate & 45 and $31.91 \%$ & $96 a n d 68.08 \%$ \\
02 & I Standard-V Standard & 18 and $40 \%$ & 27 and $60 \%$ \\
03 & VI Standard-X Standard & 20 and $48.78 \%$ & 21 and $51.21 \%$ \\
04 & SSLC & 32 and $57.14 \%$ & 24 and $42.85 \%$ \\
05 & II PUC & 14 and 38.88 \% & 22 and $61.11 \%$ \\
06 & Degree & 20 and $83.33 \%$ & 04 and $16.66 \%$ \\
07 & Post Graduate Degree & 07 and $87.50 \%$ & 01 and $12.50 \%$ \\
08 & PhD & 03 and $75 \%$ & 01 and $25 \%$ \\
\hline
\end{tabular}

Table 5: Subject's knowledge of chronic diseases

\begin{tabular}{|c|c|c|c|}
\hline S. No. & Questions & Yes and $\%$ & No and \% \\
\hline 1. & Are you aware of chronic diseases? & 202and 56.90 & 153and 43.09 \\
\hline 2 & Do you know chronic diseases are infectious? & 167and 47.04 & 188and 52.95 \\
\hline 3 & Are you aware that age is one of the predisposing factors for chronic diseases? & 120 and 33.80 & 235 and 66.19 \\
\hline 4. & Do you know Hypertension and Diabetes Mellitus are chronic diseases? & 192and 54.08 & 163and 45.91 \\
\hline 5. & Do you know good life style habits can prevent in acquiring chronic diseases? & 178and 50.14 & 177 and 49.85 \\
\hline 6. & Do you know smoking is one of the risk factors for Hypertension, COPD? & 145 and 40.84 & 210 and 59.15 \\
\hline 7. & Do you know stress is one of the risk factor for chronic disorders? & 87 and 24.50 & 268and 75.49 \\
\hline 8. & Whether chronic disorders are curable? & 303and 85.35 & 52 and 14.64 \\
\hline 9. & Do you know more salt intake can increase blood pressure? & 254and 71.54 & 101 and 28.45 \\
\hline 10 & Whether family history is risk factor for chronic diseases? & 128and 36.05 & 227 and 63.94 \\
\hline
\end{tabular}


Are you careless at times about taking your medicine?

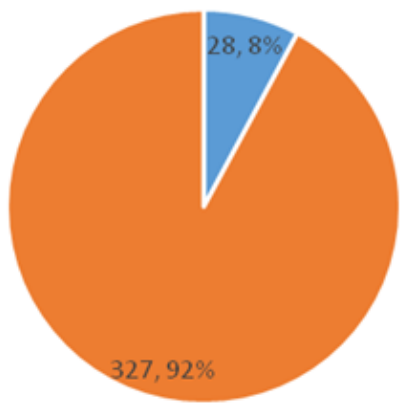

- Yes $=$ No

Fig. 2: Are you careless at time about taking your medicine

If at times you feel worse, do you stop taking your medicne?

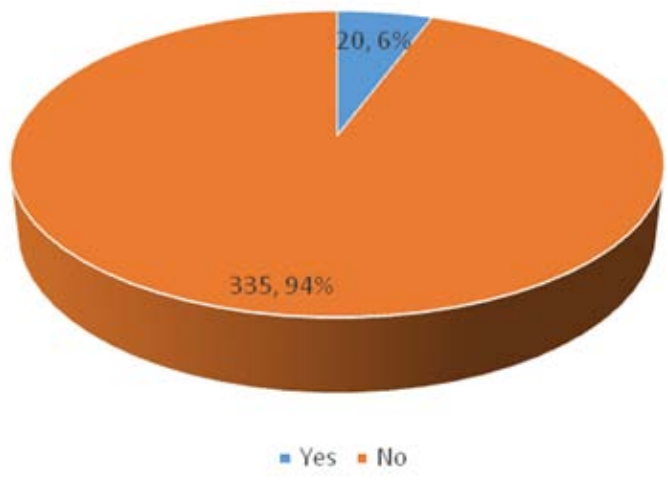

Fig. 3: If at times you feel worse, do you stop taking your medicine

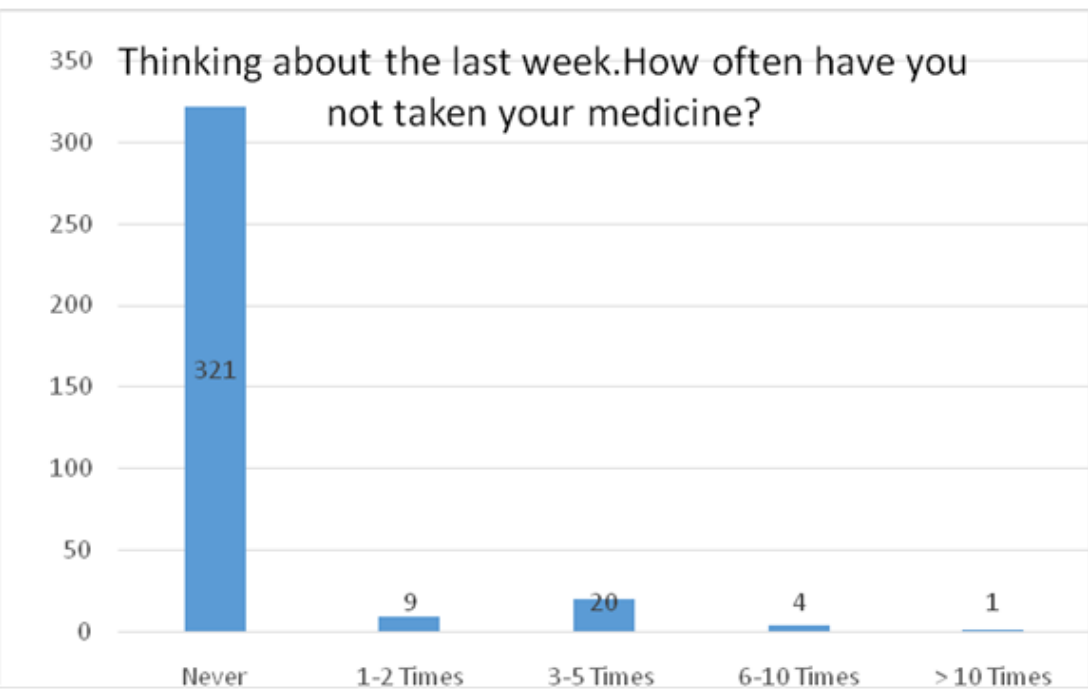

Fig. 4: Thinking about the last week how often have you not taken your medicine 
Did you not take any of your medicine over the last weekend?

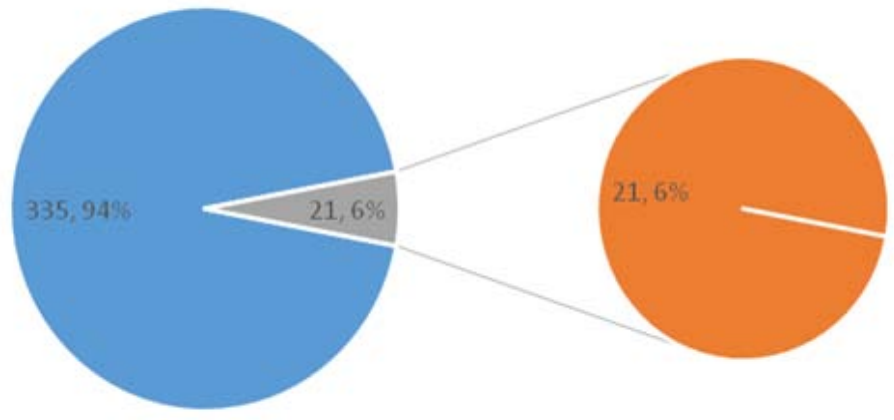

- Yes $=$ No

Fig. 5: Did you not any of your medicine over the last weekend

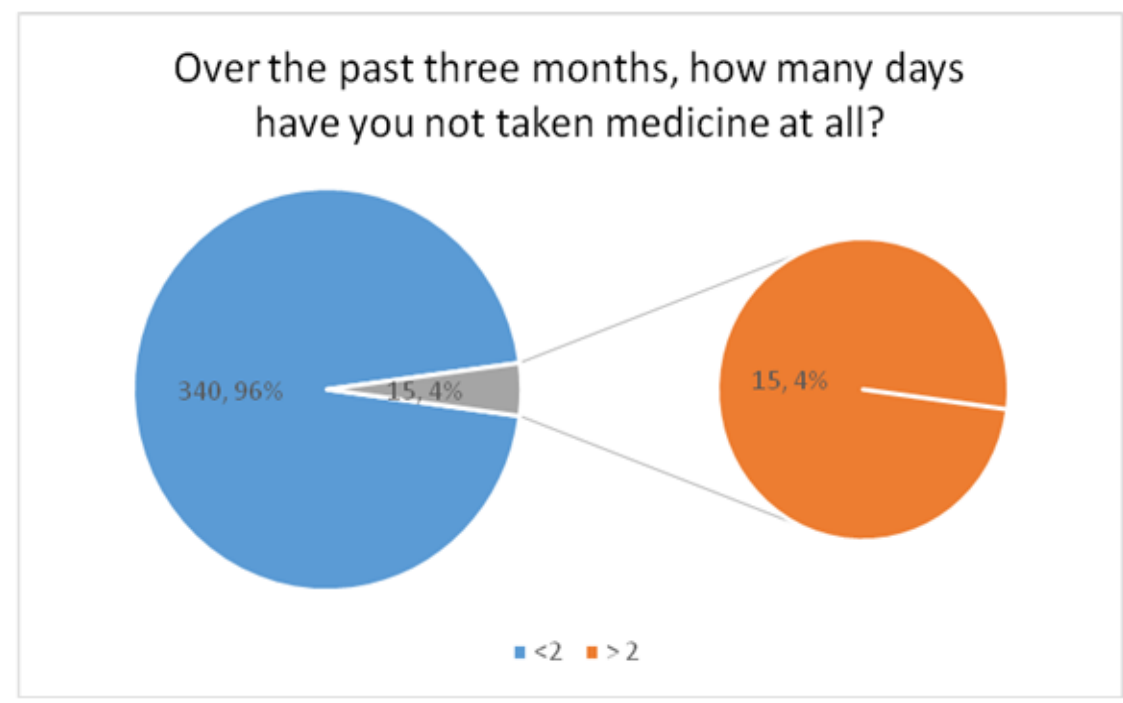

Fig. 6: Over the past three months, how many days have you not taken medicine at all

Patient Adherence Levels in Home Medicine Review

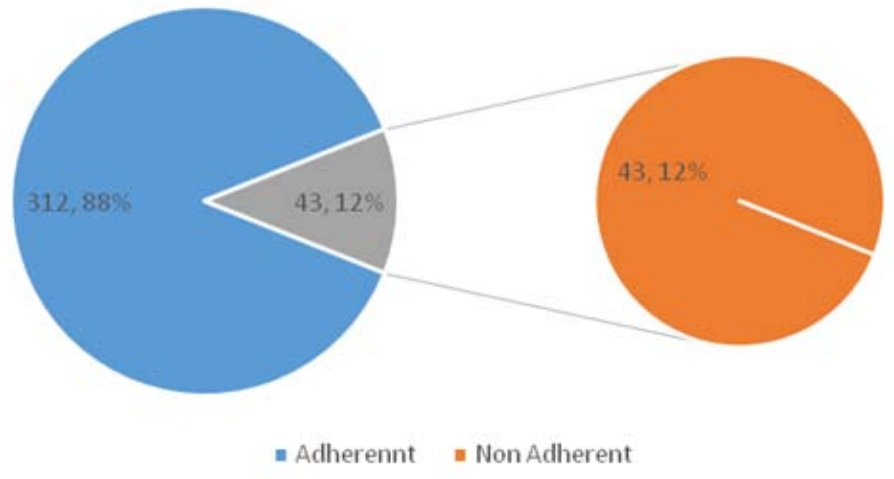

Fig. 7: Patient adherebce levels in home medicine review 


\section{CONCLUSION}

This research study concludes that elderly patients were found to adherent which was accountable for $88 \%$ followed by non-adherent was accountable for $12 \%$ as per Simplified Medication Adherence Questionnaire. The common influencing factors for poor adherence among elderly patients in this research study may be due to confusion, loss of memory, expensive medicinal product, the absence of health caretaker, a busy schedule of the day, multiple medications, loss of confidence about allopathic medicine, adverse drug reaction. Patients with good adherence in this research study showed that they have good literacy status as well as better awareness about the existing medical condition and more consciousness may be there among these patients, what will be going to happen if their medical condition is left untreated.46.29\% males and $59.58 \%$ females were adherent in this research study followed by $59.24 \%$ were adherent in the age range of 60-70 y as they were more conscious and less forgetfulness about medications as per the directions given by patient consultant which was oral feedback taken by research investigators during medication review in subjects home. Subjects with higher qualification status (i. e post graduate degree) were more adherent was reflected in our research study accountable for $87.5 \%$ due to better understanding of medical problems as well as more awareness about the consequences that will be going to happen if existing medical problems was not controlled at the right time as per subjects consultant direction. Subjects with higher qualification status were able to explain their medical problems more effectively which was observed by research investigators while collecting data of subjects during Home Medicine Review.

\section{LIMITATIONS}

The adherence and non-adherence rate of enrolled subjects was assessed only through the administered questionnaire which may not be the correct under all the circumstances as it depends upon understanding of the questions in questionnaire can vary from one subject to another subject. Therefore in order to understand the accuracy of medication adherence irrespective of medical conditions, until and unless specific biomarker is measured with respect to medical condition the medication adherence end point of the research work is arbitrary.

\section{ACKNOWLEDGEMENT}

Our humble Pranamas to his holiness feet Sri Jagadguru Shivarathri Deshikendra Mahaswamiji and all authors thank patients, doctors for cooperating to carrying out this research work in Mysore city. Without the cooperation of patients and doctors this research work would not be successful.

\section{AUTHORS CONTRIBUTIONS}

All the author have contributed equally

\section{CONFLICT OF INTERESTS}

Declare none

\section{REFERENCES}

1. S Pirasath, T Kumanan, M Guruparan. A study on knowledge, awareness, and medication adherence in patients with hypertension from a tertiary care centre from Northern Sri Lanka. Int J Hypertens 2017;1-6. Doi:10.1155/2017/9656450

2. Habtamu Dame Berisa, Mohammed Gebre Dedefo. Nonadherence related factors to antihypertensive medications among hypertensive patients on follow up at nedjo general hospital in West Ethiopia. Open Public Health J 2017;11:62-71.

3. EJ Rocella, V Burt, MJ Horan, J Cutler. Changes in hypertension awareness, treatment, and control rates 20-Year trend data. Ann Epidemiol 1993;3:547-9.

4. National High Blood Pressure Education Program. National High Blood Pressure Education Program Working Group Report on Primary Prevention of Hypertension. Bethesda, MD: U. S. Department of Health and Human Service, National Heart, Lung, and Blood Institute; NIH publication no. 93-2669; 1993.

5. VL Burt, P Whelton, EJ Roccella. Prevalence of hypertension in the US adult population: results from the third National Health and Nutrition Examination Survey, 1988-1991. Hypertension 1995;25:305-13.

6. Schmeiser Rieder, U Kunze. Blood pressure awareness in Austria. A 20-year evaluation, 1978-1998. Eur Heart J 2000;21:414-20.

7. KI Kjellgren, S Svensson, J Ahlner, R Saljo. Hyperten-sive patients' knowledge of high blood pressure. Scandinavian J Primary Health Care 1997;15:188-92.

8. EL Knight, RL Bohn, PS Wang, RJ Glynn, H Mogun, J Avorn. Predictors of uncontrolled hypertension in ambulatory patients. Hypertension 2001;38:809-14.

9. R Collins, R Peto, S MacMahon. Blood pressure, stroke, and coronary heart disease. Part 2 , short-term reductions in blood pressure: overview of randomised drug trials in their epidemiological context. Lancet 1990;335:827-38.

10. JW Farquhar, N Maccoby, PD Wood. Education and communication studies in Oxford Textbook of Public Health. WW Holland, R Detels, G Knox. Eds. Oxford University Press: Oxford, UK; 1985. p. 207-21.

11. M Rosenstock, VJ Strecher, MH Becker. Social learning theory and the Health belief model. Health Education J 1988;15:17583.

12. O Prochaska, CC DiClemente, JC Norcross. In search of how people change: applications to addictive behaviours. Am Psychologist (Salma) 1992;47:1102-14.

13. V Chobanian, GL Bakris, HR Black. The seventh report of the joint national committee on prevention, detection, evaluation, and treatment of high blood pressure: the JNC 7 report. J Am Med Assoc 2003;289:2560-72.

14. Cutler. Combinations of lifestyle modification and drug treatment in management of mild-moderate hypertension: a review of randomized clinical trials. Clin Exp Hypertens 1993;15:1193-204. 